\title{
A participação social na formulação e implantação de políticas públicas
}

\author{
Jeaneth Nunes Stefaniak ${ }^{1}$
}

Alexandre Almeida Rocha ${ }^{2}$

\begin{abstract}
Sumário: 1. Introdução. 2. O que é sociedade Civil. 3. Democracia representativa versus democracia participativa. 4. A relação entre o Estado e a Sociedade Civil através da formulação de políticas públicas. 5. O espação do cidadão. 6. Conclusões.
\end{abstract}

Resumo: O artigo analisa a participação popular na elaboração e na implantação de políticas públicas. O objetivo é realizar uma revisão de literatura a partir de referenciais teóricos que apontam os entraves a participação popular na formulação das políticas públicas. Realiza-se uma análise das categorias sociedade civil, democracia representativa, democracia participativa e espaço público para demonstrar a não efetividade da participação social e para apontar mecanismos de ampliação desta participação. Os resultados demonstram que o regime de governo democrático-representativo, tal com está estruturado, se constitui em fator negativo para a efetiva participação dos cidadãos na elaboração e implantação de políticas públicas.

\section{THE SOCIAL PARTICIPATION IN THE ELABORATION AND THE IMPLANTATION OF PUBLIC POLICIES}

Palavras-chave: Participação Social; Políticas Públicas; Democracia; Sociedade Civil; Efetivação de Direitos.

\begin{abstract}
The article analyses the social participation in the elaboration of public policies. The aim is to realize a literature review from theoretical framework which point hindrances to the social engagement in the formulation of public policies. The analysis of the categories civil society, representative democracy, participative democracy and public space was realized to demonstrate the ineffectiveness of social engagement and to point mechanisms that enlarge this engagement. The results demonstrated that the representative democratic governance system, as it is structured, constitutes in a negative factor to the effective engagement of citizens in the elaboration and the implantation of public policy.
\end{abstract}

Key-Words: $\quad$ Social Participation, Public Policies, Democracy; Civil Society; Effectiveness of Rights.

\footnotetext{
${ }^{1}$ Doutora em Direito Econômico e Social da Pontifícia Universidade Católica do Paraná e professora Adjunta da Universidade Estadual de Ponta Grossa.

2 Doutor em Ciências Sociais Aplicadas pela Universidade Estadual de Ponta Grossa e Professor Adjunto nesta Instituição de Ensino Superior.
} 


\section{Introdução}

O processo de construção democrática relativamente recente no Brasil traz consigo importante debate acerca da participação popular na formulação e implantação das políticas públicas. A sociedade civil brasileira por sua história marcada pela diversidade cultural e estrutura de poder que deriva já do período colonial, impôs um governo dominado pelo coronelismo $^{3}$, e a elite política forma-se por grupos fechados, constituindo-se em estamentos, perpetuando-se, assim, no poder. Tais características ainda se observam em alguns municípios brasileiros.

Ao longo desse período histórico a participação política da população era muito incipiente, os poucos movimentos sociais eram criminalizados, como por exemplo, atente-se para a luta dos movimentos sociais por acesso a terra. Este quadro sofreu modificações ao longo do século XX, num primeiro momento, com o crescente processo de urbanização, seguido da autorização do voto feminino na década de 30 , industrialização que levou a organização dos sindicatos, fatores estes que determinaram uma profunda mudança no cenário dos espaços públicos, sem, contudo, implicar em emancipação do sujeito. Diz Schwartzman (2007, p. 210):

No caso brasileiro, a coexistência de um Estado com fortes características
neopatrimoniais levou, no passado, à tentativa de organização da sociedade em
termos corporativos tradicionais, criando uma estrutura legal de enquadramento e
representação de classes que perdura até hoje. Ao mesmo tempo, no entanto, o
mercado se expandia, a sociedade se tornava mais complexa, e formas autônomas de
organização e participação política eram criadas. O termo "cooptação política",
utilizado neste livro, busca captar o tipo de relacionamento entre estes dois sistemas
de participação, ou seja, o processo pelo qual o Estado tratava, e, ainda trata, de
submeter a sua tutela formas autônomas de participação. Uma parte importante do
sistema de cooptação criado a partir do regime Vargas foi o Ministério do Trabalho
e o sistema previdenciário, mais tarde transformados em capital político do Partido
trabalhista brasileiro. Era um sistema de tipo corporativo, na medida em que ligava
todo um setor da sociedade ao Estado e tratava de proporcionar direitos sociais e
econômicos especiais a seus participantes - aposentadoria, salário mínimo,
assistência médica, etc. - fora do mercado. Era um sistema controlado de cima, e
com relativamente pouca participação nas bases, mas utilizado com bastante eficácia
nas disputas eleitorais no mercado político aberto para garantir a continuidade dos
detentores do poder. Os sistemas de cooptação ocupam um lugar intermediário entre
os sistemas corporativos e a política aberta de grupos de interesse. Quando são
efetivos, tendem a reduzir o conflito político pela limitação de seu escopo, ao
estabelecer monopólios irredutíveis de privilégios. Eles criam, ao mesmo tempo,

\footnotetext{
${ }^{3}$ Sistema que articulava a elite governamental das capitais e a elite de fazendeiros do interior, numa oligarquia até certo ponto coesa.
}

Revista de Teorias da Democracia e Direitos Políticos | e-ISSN: 2525-9660 | Porto Alegre | v. 4 | n. 2 |

p. 80-99 | Jul/Dez. 2018 
estruturas de participação política débeis, sem consistência interna e capacidade organizacional própria.

Com o advento da ditadura militar, nos anos 60, a sociedade civil brasileira, sofre um recrudescimento, face ao autoritarismo político, que baniu movimentos populares, desmantelou organizações civis e vedou qualquer mobilização popular. O regime militar ditatorial impôs grande obstáculo à construção da cidadania e participação política. O projeto político do governo autoritário tinha como base a modernização do país o que levou ao processo maior de urbanização. O Brasil efetivamente se torna um país urbano, com todas as consequências dessa caracterização, emergindo problemas sociais antes inexistentes.

É nas cidades brasileiras que tem início o foco de resistência à ação autoritária do Estado e a luta em prol da democratização da nação ${ }^{4}$. A reorganização de espaços públicos, distintos do espaço estatal, leva a novas práticas sociais, tais como pressão política para atendimento de demandas sociais. A transição democrática iniciada na década de 70, marcadamente com as lutas contra ditadura militar, ganhou impulso notável nos anos 80, permitindo a reorganização de diversos setores, contribuindo para o ressurgimento da organização social no país, ou melhor, para a refundação efetiva da sociedade civil no Brasil.

Necessário se faz esclarecer que o regime militar ditatorial, que perdurou por vinte e um anos, de 1964 a 1985, conforme leciona Piovesan (2009, p. 78), começa a ruir por um processo de abertura política que se inicia dentro do próprio regime, não por concessão dos militares, mas pela pressão da sociedade civil, que ao longo desse período, se reorganizou e se fortaleceu. A partir de 1988 inicia-se a reestruturação das instituições democráticas sindicatos, partidos políticos, associações civis -, amparadas pelos princípios constitucionais de liberdade de participação, de imprensa, liberdade sindical e, especialmente, liberdade de manifestação.

Esse processo de reorganização política e social, não é linear sofrendo vários revezes, em função da adoção de políticas neoliberais, nas décadas de 80 e 90, que ao mesmo tempo em que agravam problemas sociais, ora forçam a organização popular em busca de melhores condições de vida, ora, amortecem esta organização, com o estabelecimento de políticas públicas assistencialistas, que objetivam contornar situações emergenciais. Este novo

\footnotetext{
${ }^{4}$ Segundo Avritzer (2002, p. 18): é a partir de meados dos anos 70, começa a ocorrer no Brasil o que se convencionou chamar de surgimento de uma sociedade civil autônoma e democrática. Tal fato está relacionado com o fenômeno de um crescimento exponencial das associações civis, em especial das associações comunitárias. - verificar a referência bibliográfica - não consta nas referências ao final do trabalho.
} 
cenário é determinante para se avaliar a capacidade de mobilização da sociedade civil, sua forma de se organizar e intervir na elaboração e implantação das políticas públicas.

O objetivo deste estudo de revisão bibliográfica é analisar, sob a ótica das pesquisas realizadas por teóricos das ciências sociais que investigaram casos concretos de participação popular nos espaços públicos, e constataram a eficiência ou não, da participação popular na formulação das políticas públicas numa perspectiva de que é através da mobilização popular que se constrói a cidadania, e consequentemente uma sociedade democrática.

Para construir esta reflexão, necessário se faz investigar os conceitos de sociedade civil, democracia representativa e participativa, espaços públicos, participação popular, políticas públicas e especialmente de cidadania. A partir desse conjunto teórico, lançar um olhar crítico acerca do estágio de organização da sociedade civil brasileira, através de análise dos instrumentos jurídicos construídos idealmente para permitir esta participação popular, não só para dar legitimidade às políticas públicas, mas supostamente para comprometer a sociedade com objetivos da nação.

\section{A categoria sociedade civil}

Conceituar sociedade civil não é uma tarefa simples, por existir uma diversidade considerável de leituras, que tentam construir um sentido abrangente para esta categoria, que se popularizou notadamente a partir dos anos 80 e que possui distintos significados, dependendo da posição teórica que se quer defender 5 .

Historicamente o termo foi utilizado por iluministas do século XVIII, sendo tratado por Hobbes (1992, p. 65), Locke, Rousseau, Montesquieu, Hume no sentido de se contrapor ao isolamento dos indivíduos, e confundindo inclusive com o conceito de Estado, na perspectiva de que o Estado e a sociedade civil são construídos com base nos princípios de cidadania. Nesta mesma perspectiva Kant (apud BOBBIO, 1982, p. 27) define sociedade civil, identificada com uma sociedade fundada no direito.

Novos delineamentos para uma concepção de sociedade civil se dá com Hegel (apud BOBBIO, 1982, p. 27), que vê esta categoria como um estágio de relação dialética entre a

\footnotetext{
${ }^{5}$ Acerca das dificuldades de entendimento e conceituação de sociedade civil, consulte-se, dentre outros, a excelente obra: LUIZ, Danuta E. Cantoia (org.). Sociedade Civil e democracia: expressões contemporâneas. São Paulo: Veras Editora, 2010.
}

Revista de Teorias da Democracia e Direitos Políticos | e-ISSN: 2525-9660 | Porto Alegre | v. 4 | n. 2 |

p. 80-99 | Jul/Dez. 2018 
família e o Estado, e que de modo amplo comporta organizações sociais, associações, comunidade. Constituindo-se em espaços que favorecem a interação entre o individuo e o Estado, possibilitando o envolvimento dos cidadãos na vida pública. Nesta linha de reflexão, Tocqueville $^{6}$ ofereceu importante contribuição que influenciou a inúmeros estudiosos da sociedade civil, ao colocar no cerne da construção de uma sociedade democrática o associativismo e a auto-organização.

Marx (1980, p. 85), em resposta crítica a visão hegeliana, diz que a sociedade civil reflete o antagonismo de classes que se desenvolveu apenas a partir da sociedade burguesa, que passa a ser uma sociedade de classes, compreendendo as relações materiais dos indivíduos, o Estado é o reflexo da sociedade civil, e atua no sentido de mantê-la tal como é. Nesta perspectiva sociedade civil é a base para edificação da superestrutura política e jurídica criada com objetivo de manter o modo de produção capitalista.

Fundamental para a compreensão do conceito de sociedade civil é o pensamento de Gramsci (apud BOBBIO, 1982, p. 48), que a concebe como a esfera privada ou não estatal, que é o âmbito do consenso, ao contrário da sociedade política, que é a arena das instituições políticas e do controle legal, atua no âmbito da força. Com a superação da hegemonia burguesa, se dará a absorção da sociedade política pela sociedade civil, que será capaz de regular-se a si mesma, levando a extinção do Estado. Simionato (2010, p. 50-51), ao realizar uma análise das abordagens teóricas acerca da categoria sociedade civil, centra-se na leitura que faz Gramsci e conclui:

Isto posto, é a partir do eixo teórico marxista gramsciano que apontamos as principais razões para defender o valor analítico da categoria sociedade civil, a partir dos seguintes argumentos.

1. É um conceito que permite pensar a sociedade civil com um espaço contraditório, atravessado por projetos de classe distintos, de organização de interesses, construção de aliança e busca do consenso entre classes e frações de classe em luta pelo mesmo projeto societário.

2. É arena de convencimento, de agregação, de superação de interesses corporativos e particularistas, de articulação das diferentes lutas parciais e cotidianas, que podem ser universalizadas em direção à construção da vontade coletiva.

3. É a esfera de 'preparação ideológica das massas', de elaboração de novos valores, visões de mundo e modos de pensar, de repolitização, orientação da ação política, formação de novas ideologias e de novos sujeitos políticos coletivos.

\footnotetext{
${ }^{6} \mathrm{Na}$ sua obra 'Da democracia na América', escrita em 1835, onde enaltecia o sistema político dos Estados Unidos.
} 
4. Implica na luta pelo poder e na construção de uma contra-hegemonia direcionada à emancipação humana, com vistas à superação entre governantes e governados, dirigentes e dirigidos.

5. É espaço de construção do socialismo, por meio de um processo progressivo de democratização e de organização da participação popular.

6. É espaço de luta pela hegemonia, para a absorção da sociedade política pela sociedade civil, com a consequente socialização dos bens econômicos, políticos e culturais, ou seja, a construção do 'Estado ético, integral' sintetizado no projeto socialista.

Acolhe-se, nos estreitos limites do presente trabalho, a definição gramsciana, por entender, que está situada na esfera privada, autônoma do Estado e, uma vez organizada, é capaz de regular-se e intervir decisivamente nos seus destinos.

\section{Democracia representativa versus democracia participativa}

O Brasil anuncia-se no artigo $1^{\circ}$ da Constituição Federal, como uma República, que é o tipo de governo adotado e, como um Estado Democrático de direito, fundamentado na cidadania, sob o regime da democracia, que permite ao povo o exercício do poder por meio de representantes eleitos, ou diretamente, conforme os instrumentos colocados à disposição dos cidadãos ${ }^{7}$.

Efetivamente o poder político, num regime de democracia representativa, encontra-se nas mãos dos representantes eleitos pelo voto popular em eleições periódicas e, acrescenta elementos da democracia direta, em que o poder político é exercido diretamente pelo povo. O sistema traz a idéia de que a legitimidade do poder político se dá, conforme se procura inserir a população no processo decisório das políticas adotadas pelo governo, ou em outros termos, quando as políticas adotadas reflitam os anseios da população, e assim sendo, a participação popular é a régua que mede esta legitimação.

O fundamento político-filosófico que determina a eficiência ou deficiência da participação popular na elaboração de políticas públicas é a cidadania e esta é por conseqüência oriunda do tipo de democracia que se adota para uma determinada sociedade.

No Brasil adotou-se o regime da democracia semidireta, conforme se pode observar do texto constitucional, segundo a qual o povo como titular do poder, o exerce por meio dos seus representantes eleitos por sufrágio universal, ou seja, vivemos uma democracia representativa, também chamada de indireta, tentando, entretanto, o legislador constitucional,

\footnotetext{
${ }^{7}$ Plebiscito, referendo e iniciativa popular, conforme art. 14 da Constituição Federal de 1988.
} 
reaproximar o cidadão da arena decisória, através de instrumentos criados, que se adequadamente utilizados, poderiam levar a experiências de democracia direta.

A democracia representativa é o regime adotado por muitos países de orientação política liberal, a despeito das contradições que podem ser observadas, tais como concentração de poder e abuso de autoridade, corrupção, tais países se anunciam "democráticos".

A democracia representativa baseia-se no princípio da representação, em que o cidadão atribui a um representante o poder de tomar decisões políticas em seu nome, ocorre que, conforme Souza, “[...] a democracia indireta, desvirtuou-se a ponto de se transformar em uma falsa democracia, ou numa oligarquia liberal" (CASTORIADIS apud SOUZA, 2006, p. 41), em função do desinteresse da população que o único ato que praticam no exercício do poder político é depositar o voto, durante a eleição dos representantes, que normalmente são membros da elite econômica, ou oriundos de um grupo de interesse que se fortalece em determinada conjuntura.

Em síntese a democracia representativa é democracia aparente e conduz a muitas mazelas, econômicas, sociais, políticas e especialmente, conduz a alienação ou apatia política de uma determinada comunidade.

Por outro lado, a democracia direta, que também pode ser denominada como democracia participativa, exige uma sociedade com autonomia, para exercer diretamente o poder numa situação de autogestão, que pode levar a uma democracia radical e onde não há lugar para alienação ou apatia política, hipoteticamente isso só seria possível numa sociedade igualitária, que pressupõe igualdade econômica e social, onde os cidadãos em condições iguais participam do processo decisório.

No Brasil a trajetória das experiências de democracia direta, ganha relevância, após a Constituição de 1988, com inserção de instrumentos de participação popular, e, em especial, por inserir no art. 182, que trata da política urbana, determinou a elaboração de lei que teria

\footnotetext{
${ }^{8}$ Para a grande maioria das pessoas, da grande imprensa ao ambiente da Ciência Política, "democracia" é o tipo de regime existente nos países auto-rotulados como "democráticos", ou, pelo menos, nos mais consolidados dentre eles, da Europa Ocidental aos Estados Unidos, ao Japão e a alguns poucos outros (Canadá, Austrália...). Afora uns poucos filósofos políticos e cientistas sociais, além dos integrantes dos movimentos sociais mais combativos, raríssimos são aqueles que põem em dúvida esse, por assim dizer quase monopólio políticosimbólico-conceitual. E é mister que se esclareça, contudo, que esse é um tipo de sistema ou regime democrático - o representativo -, por sinal extremamente falho e problemático. Muito diferente dessa modalidade de democracia, e situando-se num extremo oposto, é a chamada democracia direta. (Souza, 2006, p. 39)
} 
por função regulamentar esta política de reforma urbana, dispondo sobre diretrizes gerais para ordenar o desenvolvimento das funções sociais da cidade e do bem estar dos habitantes. Tal lei, conhecido como Estatuto da Cidade, n. 10.257/2001, estabelece a obrigatoriedade da participação popular de modo direto, para definição das prioridades na gestão das $\operatorname{cidades}^{9}$. A simples interpretação literal de vários artigos do Estatuto da Cidade demonstra que o princípio da participação popular informa o espírito desta lei.

Conforme Souza (2006, p. 221), não se pode negar que o Estatuto da Cidade, constituiu-se num avanço jurídico formal, mas que por outro lado, reconhece que, no que tange a participação popular, seus dispositivos, são vagos, ambíguos e indefinidos, levando basicamente a um processo meramente consultivo dessa população interessada, de modo amplamente controlado pelas autoridades municipais, constituindo-se em pseudoparticipação.

A despeito das limitações do Estatuto da Cidade, no que se refere à participação popular, com uma função deliberativa, na gestão da cidade, de modo pontual, o que seria uma situação ideal, alguns exemplos de democracia participativa foram colocados em prática, como por exemplo, no orçamento participativo de Porto Alegre, capital gaucha ${ }^{10}$.

A propagada experiência de democracia participativa, no entanto, se resumia numa incipiente participação dos cidadãos em alguns aspectos ${ }^{11}$ e sempre coordenados pelo Estado. A experiência de Porto Alegre, estendida ao âmbito estadual, quando Olívio Dutra se elegeu governador, não pode ser considerada como um caso de democracia direta, dada as limitações com que foi implementada, conforme esclarece Souza (2006, p. 249) ${ }^{12}$, com significativa exemplificação.

\footnotetext{
${ }^{9} \mathrm{O}$ art. $2^{\circ}$ do Estatuto dispõe que a política urbana tem como diretriz a gestão democrática por meio da participação da população e de associações representativas dos vários segmentos da comunidade na formulação, execução e acompanhamento de planos, programas e projetos de desenvolvimento urbano. E no Art. $4^{\circ}$ enumera como instrumento a ser utilizado, a gestão orçamentária participativa, o referendo popular e plebiscito. Além de vários outros, art. 33, art. 40, art. 43, art. 44 e art. 45.

${ }^{10}$ Segundo Souza (2006, p. 236): “[...] o orçamento participativo de Porto Alegre, despontou na década de 90, como uma das mais notáveis experiências de gestão urbana participativa, implementado após eleição de Olívio Dutra para prefeito em 1989. Esclarece ainda o Autor, que embora implementado pelo governo petista, não foi obra desde, pois o pioneiro na exigência da participação popular no processo orçamentário foi a UAMPA União das Associações de Moradores de Porto Alegre".

${ }^{11}$ A metodologia adotada conduziu a organização de um Conselho do Orçamento Participativo, sendo que os conselheiros eram representantes eleitos pela população e outros indicados pela sociedade civil organizada em associações e sindicatos. E a assembléia municipal, não tinha caráter deliberativo.

${ }^{12}$ É uma tentativa de introduzir elementos de democracia direta na gestão da cidade (ou mais precisamente, do município), permanecendo, como não poderia deixar de ser, no interior dos marcos institucionais da 'oligarquia liberal' ou oligarquia eletiva que é a dita democracia representativa.
} 
Além da experiência de Porto Alegre, Santos (2008, p. 158) esclarece que existem outros exemplos de redistribuição democrática de recursos que se tornou possível através da combinação de democracia participativa e representativa, mas que se resumiram a aplicações sem amplitude, bastante limitadas, baseando-se tão somente em utilização de recursos do Estado, deixando de fora os modos de arrecadação de recursos, para os quais o autor, considera de relevante importância, e que ele denomina de 'fiscalidade participativa'.

A ausência de participação popular na elaboração das políticas fundamentais, que vão gerir o destino da sociedade leva a uma falta de legitimação do exercício do poder político e assim a inúmeras mazelas já citadas, entre elas ao câncer da corrupção. Desqualificar a participação popular, pelas dificuldades na implantação de metodologias que permitem esta participação é desacreditar no futuro da humanidade. É preciso buscar alternativas, fortalecendo organização popular que pode despertar na população o interesse pela autogestão, o comprometimento dos membros da sociedade civil conduz a legitimação das ações em torno da formulação e da efetivação das políticas públicas.

\section{A relação entre o estado e a sociedade civil na formulação de políticas públicas}

A sociedade civil distanciada da administração pública, por conta do regime da democracia indireta, leva a deslegitimação de fato do poder político e, a uma descrença generalizada quanto às políticas públicas adotadas.

Nessa linha de raciocínio, legitimação da atuação pública na formulação de políticas públicas, só pode se dar, num modelo sugerido por Habermas (1997, p. 150), na sua Teoria do agir comunicativo $^{13}$. Para este autor, um direito é válido, e, portanto, aceito, porque é fundado em argumentos racionais e especialmente se implantado o sistema de regras emanadas do povo e nessa proposta Habermasiana, a legitimidade das políticas públicas, se encontrariam, não no plano metafísico, mas no plano discursivo e procedimental. A legitimidade do Direito e consequentemente das ações do Estado, devem percorrer o caminho da busca do consenso, que só pode ser atingido naquilo que Habermas (1997, p. 150) denomina de autolegislação:

(...) mais precisamente entre a coerção do Direito, que garante um nível médio de aceitação da regra, e a idéia de auto legislação - ou da suposição da autonomia

\footnotetext{
${ }^{13}$ Para este autor "O Direito e a Democracia, situados entre facticidade e validade", para analisar as instituições jurídicas e propor um modelo onde se interpenetram justiça, razão comunicativa e modernidade.
}

Revista de Teorias da Democracia e Direitos Políticos | e-ISSN: 2525-9660 | Porto Alegre | v. 4 | n. 2 | 
política dos cidadãos associados - que resgata a pretensão da legitimidade das próprias regras, ou seja, aquilo que as torna racionalmente aceitáveis.

Compartilhar decisões, estabelecer consenso, conduz a interação social, ou seja, sociedade civil ao contribuir ativamente para definição (autonomia política) e elaboração das políticas públicas, permite o comprometimento dos cidadãos (legitimidade), para com as ações do Estado. Para enfrentar o desafio de abordar a deficiência da participação popular na formulação das políticas públicas, é necessário refletir sobre o conceito de políticas públicas, que na abordagem esclarecedora de Bucci (2006, p. 79), deve partir da análise do advento dos direitos sociais, que aparecem como um novo paradigma jurídico do Estado liberal.

Os direitos sociais, tratados como direitos de segunda dimensão ${ }^{14}$, são concebidos como demandas de prestações ativas por parte do Estado, proporcionando o atendimento de necessidades mais urgentes da população, abrangendo direitos econômicos, sociais e culturais, sendo que o atendimento de tais demandas asseguram condições de igualdade aos cidadãos para que possam exercer os direitos de primeira dimensão, os direitos-liberdades. Weis (2014, p. 54), acolhendo a crítica a questão da geração ou dimensão dos direitos fundamentais, adverte que a vinculação a questão geracional dos direitos prejudica a elaboração de políticas públicas:

(...) além de consolidar a imprecisão da expressão em face da noção contemporânea
dos direitos humanos, pode se prestar a justificar políticas públicas que não
reconhecem indivisibilidade da dignidade humana e, portanto, dos direitos
fundamentais, geralmente em detrimento da implementação dos direitos
econômicos, sociais e culturais ou do respeito aos direitos civis e políticos previstos
nos tratados internacionais já antes citados.

A modificação paradigmática, na análise de Bucci, veio com a normatização dos direitos sociais, constitucionalizados, ao longo do século XX, inicialmente com a Constituição do México, em 1917 e na da Alemanha, em 1919, seguido por outros Estados, inclusive o Brasil, a partir de 1934, sendo que na Constituição de 1988, encontram-se num disposto no Artigo $6^{\circ}$, que enumera como direitos sociais, a educação, a saúde, o trabalho, a moradia, o lazer, a segurança, a previdência social, a proteção à maternidade e à infância, a assistência aos desamparados. Reconhecer e positivar direitos sociais, como direitos fundamentais do

\footnotetext{
${ }^{14} \mathrm{~A}$ referência à dimensão dos direitos fundamentais se faz para elucidar o momento em que o Estado atrai para si a responsabilidade de realizar as ações necessárias para a concretização dos direitos. Compartilha-se, aqui, da crítica formula pelos teóricos à questão da geração dos direitos ou mesmo da dimensão dos direitos fundamentais. Acolhe-se, aqui, o entendimento de os direitos são interdependentes e indivisíveis.
}

Revista de Teorias da Democracia e Direitos Políticos | e-ISSN: 2525-9660 | Porto Alegre | v. 4 | n. 2 |

p. 80-99 | Jul/Dez. 2018 
cidadão, exige uma intervenção do Estado na área econômica, o que leva ao paradigma do Estado intervencionista, também caracterizado como Estado social.

Hesse (1996, p. 249), explica que os direitos sociais não efetivados, não conduzem a um direito de ação contra o Estado, já que não se tratam de direitos subjetivos, mas são direitos ligados ação do Estado e, dependentes dos programas e políticas estatais.

Assim sendo, exigência de atuação por parte do Estado para atender as carências dos cidadãos, liga tais direitos sociais diretamente ao conceito de políticas públicas, permitindo traduzir, políticas públicas, como o Estado em ação, obviamente, que esta deve estar voltada para objetivos específicos ${ }^{15}$, para atender necessidades pontuais da população.

Necessário se faz ainda enfatizar na linha de reflexão do eminente jurista Sarlet (2002, p. 75), que só onde se asseguram condições mínimas de sobrevivência, é que há possibilidade de se falar em dignidade da pessoa humana.

Importante ainda para o contexto deste trabalho é ainda enfocar que as políticas governamentais (programas de ação) e as políticas de Estado, estão vinculadas aos objetivos fundamentais estabelecidos no texto constitucional, que no caso do Brasil, estão elencados no artigo $3^{\circ}$, da Constituição Federal ${ }^{16}$, por óbvio, que as políticas públicas, adotadas, devem estar vinculadas, ou buscar atingir tais objetivos estabelecidos na Constituição. Este artigo terceiro é o núcleo material de adoção de uma constituição dirigente.

Bucci (2006, p. 45) citando Comparato, num importante trabalho, sobre o juízo de constitucionalidade de políticas públicas, em que este renomado professor, diferencia a categoria de políticas públicas, das normas e atos que a compõem. Sustentando que o juízo de validade desta, não se confunde com o juízo de validade da política. Podendo uma lei emanada por força de uma política pública, ser inconstitucional, não sendo a política pública, por essa causa, inconstitucional. Por essa ótica, sustenta a autora, que o inverso, também é verdadeiro, podendo uma política pública ser considerada inconstitucional, se ferir norma ou diretriz constitucional.

Mas efetivamente cabe ainda o questionamento, acerca da natureza jurídica das políticas públicas, pois não se confundem com normas ou princípios, são conforme Bucci,

\footnotetext{
${ }^{15}$ Segundo Bucci (2006, p. 19): “A política pública tem um componente de ação estratégica, isto é, incorpora elementos sobre a ação necessária e possível naquele momento determinado, naquele conjunto institucional e projeta-os para o futuro mais próximo".

${ }^{16}$ Este artigo dispõe que os objetivos fundamentais da República Federativa do Brasil são: a construção de uma sociedade livre, justa e solidária; garantir o desenvolvimento nacional; promover o bem de todos, sem preconceitos de origem, raça, sexo, cor, idade e quaisquer outras formas de discriminação.
} 
apud Dworkin, um padrão, ou standard, que estabelece um objetivo a ser atingido, seja, econômico, político ou social. Na análise da autora, aparecem como uma categoria diferenciada, de preenchimento de espaços normativos, e que por deterem esta qualidade ultrapassam os limites normativos, já que possuem objetivos específicos e são pontualmente direcionados.

Finalmente Bucci, justificando que mesmo não sendo política pública uma categoria jurídico-formal, é necessário estabelecer um conceito jurídico, porque é no direito que se assenta o diálogo entre o poder legislativo, o governo e a administração pública. A operacionalização das políticas públicas, trilha o caminho determinado pelas diretrizes constitucionais. E assim sendo, a autora, fornece o seguinte conceito para políticas públicas:

Política pública é o programa de ação governamental que resulta de um processo ou conjunto de processos juridicamente regulados - processo eleitoral, processo de planejamento, processo de governo, processo orçamentário, processo legislativo, processo administrativo, processo judicial - visando coordenar os meios à disposição do Estado e as atividades privadas, para a realização de objetivos socialmente relevantes e politicamente determinados. Como tipo ideal, a política pública deve visar à realização de objetivos definidos, expressando a seleção de prioridades, a reserva de meios necessários a sua consecução e o intervalo de tempo em que espera o atingimento dos resultados (BUCCI, 2006, p. 39).

O que se observa da proposição contida no conceito formulado por Bucci, é a vinculação das políticas públicas aos objetivos constantes no projeto político estatal e dos valores nele contidos. Ao mesmo tempo em que é o projeto político do Estado que vai vincular as políticas públicas, e, é este mesmo projeto que o limita. A efetivação desse projeto político depende por conseqüência, de uma serie de elementos, já aqui analisados, dentre eles o regime adotado para exercício do poder político que na linha de reflexão do presente ensaio, só terá legitimidade na medida em que promover a efetiva participação popular fortalecendo o compromisso da sociedade civil com este projeto político.

É fundamental a existência de instrumentos jurídicos e políticos, garantidos no ordenamento jurídico, para que se dê uma resposta às demandas e aos anseios dos cidadãos e que possibilite a participação popular na formulação de políticas públicas, devendo ter por objetivo o atendimento de tais necessidades. Agregando esta reflexão, já se pode formular uma primeira hipótese acerca da problemática que levou a elaboração do presente trabalho, qual seja, que os limites da participação popular na formulação de políticas públicas é estrutural e está enraizado no projeto político brasileiro; é endêmico. 
O complemento das respostas a serem oferecidas à problemática da pesquisa depende da compreensão das categorias espaço público e cidadania, as quais permitem desvelar um olhar em que a mesma sociedade civil, engessada pelos instrumentos jurídicos e políticos positivados, possa encontrar uma área de escape, para a efetivação da participação popular.

\section{O Espaço do cidadão ${ }^{17}$}

O enfoque dado no presente ensaio sustenta que é na sociedade civil o real espaço do cidadão, onde este tem potencialmente condições de participar ativamente das decisões que são tomadas pelos representantes eleitos para cargos públicos e que determinaram os destinos da sociedade. A participação social tem como pressuposto de existência o exercício da cidadania, cujo conceito merece ser explorado, numa ótica interdisciplinar que permita entender a amplitude e importância desse novo tipo de cidadania exigida no espaço do cidadão.

O saudoso professor Milton Santos formula dois questionamentos que permitem inaugurar esta reflexão: $1^{\circ}$ ) Quantos habitantes, no Brasil, são cidadãos? E quantos nem sequer sabem que não o são? (SANTOS, 1987, p. 63).

Para iniciar a reflexão sobre cidadania, é necessário buscar no seu conceito tão caro aos direitos humanos, pois com estes se confunde, historicamente e nas palavras de Dallari (1998, p. 44), cidadania expressa um conjunto de direitos que permite à pessoa participar da vida e do governo de seu povo. Quem não tem cidadania está marginalizado, excluído da vida social e da tomada de decisões, assumindo uma posição de inferioridade dentro do grupo social a que pertence. Nesta linha de raciocínio, não há cidadania se não houver participação social, não há se falar em cidadania.

A noção de cidadania está vinculada com os direitos humanos, na perspectiva das liberdades humanas, e pressupõe a existência de direitos civis, políticos e por óbvio também da existência dos direitos sociais (DALLARI, 1998, p. 58). No conceito de cidadania, liga-se

\footnotetext{
${ }^{17}$ A denominação deste capítulo é o título do livro do professor Milton Santos, publicado em 1987, pela Editora Nobel de São Paulo.
}

Revista de Teorias da Democracia e Direitos Políticos | e-ISSN: 2525-9660 | Porto Alegre | v. 4 | n. 2 |

p. 80-99 | Jul/Dez. 2018 
o de liberdade e de igualdade, e estes se ligam entre si, pois não há como conceber um individuo excluído de direitos básicos, como cidadão ${ }^{18}$.

A cidadania não é um mero status do individuo investido na condição de pessoa detentora de direitos reconhecidos pela ordem jurídica, esta, em verdade, se constrói no cotidiano do cidadão, constituindo-se num permanente aprendizado, oriundo de suas práticas no interior desse espaço público, num permanente exercício de prerrogativas, ou poderes inerentes a sua condição membro da sociedade. A cidadania então se constituirá numa sensação de pertencimento a uma sociedade, ou, como ensina Santos (1987, p. 65): “[...] cidadania, sem dúvida, se aprende. É assim que ela se torna um estado de espírito, enraizado na cultura. É, talvez, nesse sentido, que se costuma dizer que a liberdade não é uma dádiva, mas uma conquista, uma conquista a manter".

A noção de cidadania no Brasil, sob esta ótica interdisciplinar, dentro de um contexto histórico e em função da grande desigualdade social, não passa de uma definição abstrata, naquela linha de que cidadão é simplesmente aquele que exerce o direito de voto. Historicamente se justifica no sentido de que a retomada da democracia é algo muito novo, recém-saída de um regime autoritário, a nação ainda busca caminhos a percorrer para a implantação de uma sociedade verdadeiramente democrática. Sob o aspecto do desiquilíbrio social, o Brasil, é um país de profundas injustiças, com um terço de sua população vivendo na condição de pobreza, e assim sendo cidadania, condição sine qua non para a democrácia, no Brasil é um conceito mutilado.

Nas últimas décadas, no entanto, grandes avanços ocorreram no sentido da busca pela construção democrática no Brasil, as experiências mesmo que tímidas de democracia participativa permitem idealizar a transformação da noção de cidadania e os espaços sem cidadãos, podem então se converter em sociedade civil, composta de inúmeros espaços públicos, onde o individuo possa se fazer ouvir.

A refundação da sociedade civil, somente possível com a reorganização das inúmeras organizações da sociedade, partidos políticos, associações civis, de gênero, de classe, sindicatos, movimentos sociais, exige que seus membros exerçam suas prerrogativas de

\footnotetext{
${ }^{18}$ Complementa Dallari (1998, p. 63): "O respeito ao individuo é a consagração da cidadania, pela qual uma lista de princípios gerais e abstratos se impõe como um corpo de direitos concretos individualizados”.
}

Revista de Teorias da Democracia e Direitos Políticos | e-ISSN: 2525-9660 | Porto Alegre | v. 4 | n. 2 | 
cidadãos, na perspectiva de fazer valer seus direitos fundamentais ${ }^{19}$. A realização do individuo se dá na medida em que este se realiza como cidadão, enquanto membro de uma comunidade, o que é consequencia de uma sociedade constituida por espaços que permitam esta emancipação social. A cidadania só se pode efetivar num contexto de emancipatório (SANTOS, 1987, p. 67).

\begin{abstract}
A luta pela cidadania não se esgota na confecção de uma lei ou da Constituição porque a lei é apenas uma concreção, um momento finito de um debate filosófico sempre inacabado. Assim como o individuo deve estar sempre vigiando a si mesmo para não se enredar pela alienação circundante, assim o cidadão, a partir das conquistas obtidas, tem de permanecer alerta para garantir e ampliar sua cidadania.
\end{abstract}

Uma questão relevante, no entanto é levantada por Santos (2008, p. 45), ao afirmar que a emancipação social pressupõe uma refundação democrática da administração pública e do que ele denomina de terceiro setor $^{20}$, ao que parece vai se confundir com a discutida sociedade civil organizada em instituições sob a égide de interesses públicos e coletivos previamente definidos, pelos seus membros. Além das instituições sociais é possível incluír alguns espaços públicos que tem função consultiva e especialmente deliberativa com respeito às políticas públicas ${ }^{21}$, posto que a cidadania será construída no comprometimento do cidadão com os destinos da comunidade.

Quanto à refundação democrática da administração pública exige uma articulação entre o Estado e a sociedade civil, não um substituindo ou anulando o outro, mas com atuação em complementação um do outro, o que vai exigir a transformação da cidadania abstrata em cidadania ativa, que pode ser incentivada por ações ${ }^{22}$ de um Estado comprometido com esta emancipação social, sob uma nova teoria democrática.

\footnotetext{
${ }^{19}$ Segundo Santos (1987, p. 67): "Entre a realização plena do individuo - ou, simplesmente, a vontade de ser livre - e a realização do cidadão encontram-se as diversas organizações que estruturam a vida social"

${ }^{20}$ Santos $(2008$, p. 45$)$ explica que o terceiro setor são organizações sociais privadas, sem fins lucrativos, com finalidade pública ou coletiva, sem se enquadra no conceito de estatal: cooperativas, organizações comunitárias ou de base, associações mutualistas, associações não lucrativas, organizações não governamentais, organizações quase-não governamentais, organizações de voluntariado, etc.

${ }^{21}$ Dagnino, ao refletir sobre sociedade civil e os espaços públicos no Brasil, esclarece: (...) com respeito às políticas públicas, os diferentes conselhos e os orçamentos Participativos, até os espaços de encontros mais pontuais, que se destinam à execução dessas políticas (parcerias com ONGs e com o MST). Incluímos espaços de relações que se estruturam a partir da sociedade civil, cujo objetivo principal é a articulação de seus vários setores para exercer pressão e monitoramento sobre a atuação do Estado (FNRU e ONGs).

${ }^{22}$ Santos (2008, p. 370), cita como exemplo a proposta de inserção social de Rosanvallon em 1995, para a França, denominado de RMI - rendimento mínimo de inserção, garantido em troca de participação concreta do titular desse direito em atividades sociais, de formação profissional e de assistência a necessitados.
} 
Em síntese, a proposta de Santos (2008) para a transformação da realidade, exige não apenas uma reforma, mas uma verdadeira revolução, não só no âmbito da administração pública - que pressupõe a adoção de um novo projeto político, mas especialmente no âmbito da sociedade civil, com a necessária reformulação do conteúdo de cidadania.

Este novo projeto político a ser adotado, baseado numa refundação democrática do Estado e da sociedade civil, tendo como valor fundamental a dignidade da pessoa humana ${ }^{23}$, e deve partir de experiências que já vem sendo utilizadas em vários países, por meio de instituições híbridas de caráter cidadão-estatal, em área sensíveis da vida pública, na qual o Orçamento Participativo do Brasil, é um exemplo, mas que outros podem experenciados como as Audiências Públicas na Argentina, a Defensoria do Povo na Colombia e o Instituto Federal Eleitoral no México (OLIVEIRA, 2002, p. 354).

A sociedade civil está em processo de reestruturação a utilização desses vários instrumentos e instituições que se completam, reforça a autonomia do povo é pode levar refundação democrática da administração pública, inicialmente temas centrais de interesse público e coletivo pode aglutiniar a sociedade civil, direitos fundamentais, em especial os direitos sócio-ambientais que estão em emergência, podem se constituir no fator de interação social.

No aspecto ambiental vários exemplos práticos da construção de uma sociedade mais autonoma, consultas públicas, sobre destinação do lixo, perfil ambiental das cidades ${ }^{24}$, patrimonio histórico, vem sendo desevolvidas, numa tentativa de envolver a sociedade civil e conseguir respaldo ou obter legitimidade para ações estatais. Diversas criticas têm sido formuladas no sentido de que a população não tem sido suficientemente esclarecida e

\footnotetext{
23“"Temos por dignidade da pessoa humana a qualidade intrínseca e distintiva de cada ser humano que o faz merecedor do mesmo respeito e consideração por parte do Estado e da comunidade, implicando, neste sentido, um complexo de direitos e deveres fundamentais que assegurem a pessoa tanto contra todo e qual ato de cunho degradante e desumano, como venham a lhe garantir as condições existenciais mínimas para uma vida saudável, além de propiciar e promover sua participação ativa e co-responsável nos destinos da própria existência e da vida em comunhão com os demais seres humanos" (SARLET, 2002, p. 65)

${ }^{24} \mathrm{Em} 23$ de agosto de 2009, a sociedade da cidade Porto Alegre, será consultada para saber se na antiga área do Estaleiro Só, na Orla do Guaíba, poderão ser construídas edificações destinadas à residência. Ambientalistas se organizam para tentar impedir o projeto de empreendedores que desde 2007 manifestam interesse de construir imóveis residenciais na área. De acordo com o vice-prefeito e coordenador do processo eleitoral, José Fortunati, a prefeitura está fazendo um grande esforço para buscar novas metodologias de participação da população. "Queremos consolidar mecanismos de participação pública permanente, é direito do cidadão que reside aqui decidir sobre o futuro da sua cidade". Destacou, ainda, que a consulta de domingo será o termômetro do interesse da população em participar ativamente da história da cidade, decidindo os rumos da Capital.
} 
participa timidamente desses processos, porém é através das organizações sociais que se pode qualificar a participação cidadã.

A formulação de políticas públicas num contexto de participação cidadã gozariam inexoravelmente de legitimidade ${ }^{25}$ e funcionariam por sua vez como um canal para emancipação do indivíduo, que ali estaria inserido na qualidade de cidadão que intransigentemente busca a efetividade de seus direitos constitucionais e se sente comprometido com os destinos de sua comunidade.

\section{Considerações finais}

A proposta do presente ensaio é realizar uma reflexão sobre a participação social na formulação das políticas públicas, lançando um olhar nas deficiências ou obstáculos a essa participação. Optou-se por realizar uma analise geral, explorando conceitos de sociedade civil, democracia representativa e participativa, espaços públicos e cidadania, para se demonstrar as possibilidades da participação social na elaboração de tais políticas e suas limitações.

Ao se analisar o conceito de sociedade civil, conclui-se que os momentos que antecederam o fim do regime militar autoritário, encerrado em meados da década de 80, foram extremamente ricos para o ressurgimento desta nova sociedade, que se desenhou em contornos distintos do que historicamente existiu no Brasil enquanto nação: a luta pela democratização do país exigiu mobilização popular e a construção de organizações civis que pressionaram pelo fim da ditadura. Movimentos sociais ressurgiram e se afirmaram enquanto força política a ser considerada. Partidos políticos de oposição conquistavam espaços e realizaram experiências que foram consideradas referências de participação popular, a exemplo da capital do Rio Grande do Sul, Porto Alegre, com a implantação do orçamento participativo.

A refundação da sociedade civil também encontra espaço para se ampliar nas organizações civis que se proliferam a partir dos anos 90, organizações não governamentais, cooperativas populares, associação de mulheres e de moradores, reunidos em torno de vários

\footnotetext{
${ }^{25}$ Segundo HABERMAS (1997, p. 60):"[...] mais precisamente entre a coerção do Direito, que garante um nível médio de aceitação da regra, e a idéia de autolegislação - ou da suposição da autonomia política dos cidadãos associados - que resgata a pretensão da legitimidade das próprias regras, ou seja, aquilo que as torna racionalmente aceitáveis".
}

Revista de Teorias da Democracia e Direitos Políticos | e-ISSN: 2525-9660 | Porto Alegre | v. 4 | n. 2 | 
interesses, terra, moradia, crédito, emprego, meio ambiente entre outros, permite idealizar que se encontra em gestação um verdadeiro reaprendizado da cidadania.

Num segundo eixo, se analisou os conceitos de democracia representativa, também denominada, indireta, regime esse adotado em nosso País, onde o povo elege através do voto, os seus representantes, que então irão decidir os destinos dessa sociedade em nome de seus representados. Observa-se que este regime apesar, de ser adotado por países de orientação liberal, que se anunciam democráticos, padece de inúmeros vícios, tais como elitização e perpetuação no poder, corrupção, etc que levam a uma verdadeira oligarquia ou a uma falsa democracia.

O mais grave problema, no entanto, observado nos países onde se adota a democracia representativa, é a apatia por parte da população, que se limitam a depositar seus votos nos candidatos que se eternizam no exercício do poder político. O desinteresse popular conduz a inúmeras mazelas, em especial nos países em desenvolvimento, como é o caso brasileiro, onde políticas públicas assistencialistas são formuladas para permitir a manutenção do status quo.

O circulo vicioso da desigualdade social, alimentada por políticas excludentes, mantidas por políticas públicas assistencialistas, desfigura ou descaracteriza o cidadão, que passa a importar somente enquanto eleitor, e assim sendo, a construção de uma sociedade democrática que estaria alicerçada na cidadania deixa de ser construída.

Ao revés, a democracia participativa, que também pode ser denominada de democracia direta, permite o exercício do poder pelo próprio povo, em condições de igualdade, o que pode ser considerado democracia radical. Inúmeros são os óbices, que se levantam para a implantação de um regime de democracia direta, dentre eles a operacionalização dessa participação social. Não obstante, algumas experiências já se aconteceram e a partir delas, várias possibilidades se vislumbram, para sua realização.

O orçamento participativo da capital gaucha, Porto Alegre, ainda nos anos 90, se tornou um caso paradigmático para inúmeros estudos e propostas que possam levar a participação popular no exercício do poder político. Apesar dos desvios apontados pela esclarecedora obra de Souza (2006), que logo na introdução do livro aponta, "a guisa de préfácio: de novo essa história de participação popular?!” que as experiências e promessas que envolvem a participação popular não passam de palavrórios vazios, que levam a mistificação e a falsa participação.

Revista de Teorias da Democracia e Direitos Políticos | e-ISSN: 2525-9660 | Porto Alegre | v. 4 | n. 2 | p. 80-99 | Jul/Dez. 2018 
Além da experiência do orçamento participativo, outros exemplos podem ser reunidos, e vir a se somar, tais como: audiências públicas; consultas a população entre outros, além da interessante proposta de Santos, da "fiscalidade participativa", onde o cidadão atua como um fiscal de todo processo público, podem todos reunidos, se constituir num canal a conduzir a uma efetiva participação popular na formulação de políticas públicas. A despeito dos evidentes obstáculos que se apresentam à atuação cidadã, se conclui, na mesma perspectiva de Marcelo Lopes Souza, que ela é perfeitamente possível, e por si só compensa em muitos sentidos, e, que, o fruto dessa ação pemitirá que se começe a escrever outra história para humanidade.

\section{Referências Bibliográficas}

ALTVATER, Elmar. Os desafios da globalização e da crise ecológica para o discurso da democracia e dos direitos humanos. In Heller, Agnes e al. A Crise dos paradigmas e os desafios para o século XXI. Rio de Janeiro: Contraponto, 1999.

BOBBIO, Norberto. Estado Governo Sociedade, Para uma teoria geral da política; tradução Marco Aurélio Nogueira. - Rio de Janeiro: Paz e Terra, 1987.

O Conceito de Sociedade Civil; tradução Marco Aurélio Nogueira - Rio de Janeiro: Edições Graal, 1982.

BUCCI. Maria Paula Dallari (organizadora). Políticas Públicas: Reflexões sobre o conceito jurídico. São Paulo: Saraiva, 2006.

COMPARATO, Fábio Konder. Ensaio sobre o juízo de inconstitucionalidade de políticas públicas. Revista de Informação Legislativa, v. 35, p. 39-48, abr./jun. 1998.

DAGNINO, Evelina (org). Sociedade Civil e Espaços Públicos no Brasil. São Paulo: Paz e Terra, 2002.

DALLARI, Dalmo de Abreu. Direitos humanos e cidadania. São Paulo: Moderna, 1998.

HABERMAS, Jürgen. Direito e Democracia: entre factibilidade e validade. Rio de Janeiro: Tempo Brasileiro, 1997. 
HESSE, Konrad. Manual de Derecho Constitucional. Trad. Antonio López Pina. Madrid: Marcial Pons, 1996.

HOBBES, Thomas. Do Cidadão. Coleção: clássicos. São Paulo: Martins Fontes, 1992.

LUIZ, Danuta E. Cantoia (org.). Sociedade Civil e democracia: expressões contemporâneas. São Paulo: Veras Editora, 2010.

MARX, Karl. Crítica da Economia Política. São Paulo: Martins Fontes, 1980.

MELO, Marcus André. Estado, Governo e Políticas Públicas. In: O que ler na ciência social brasileira (1970-1995), vol. III. São Paulo: Editora Sumaré. ANPOCS, Brasília, DF, CAPES, 1999.

PIOVESAN, Flávia. Direitos Humanos e o Direito Constitucional Internacional. São Paulo: Saraiva, 2009.

SANTOS, Boaventura de Sousa. A gramática do tempo: para uma nova cultura política. 2. ed. São Paulo: Cortez, 2008.

SANTOS, Milton. O espaço do cidadão. São Paulo: Nobel, 1987.

SARLET, Ingo Wolfgang. Dignidade da pessoa humana e direitos fundamentais na Constituição Federal de 1988. Porto Alegre: Livraria do Advogado, 2002.

SCHWARTZMAN, Simon. Bases do autoritarismo brasileiro. 4. Ed. Rio de Janeiro: Publit Soluções Editoriais, 2007.

SOUZA. Marcelo Lopes. A prisão e a Agora: Reflexões em torno da democratização do planejamento e da gestão das cidades. Rio de Janeiro: Bertrand Brasil, 2006.

WEIS, Carlos. Direitos Humanos Contemporâneos. 3. ed. São Paulo: Melhoramentos, 2014.

Revista de Teorias da Democracia e Direitos Políticos | e-ISSN: 2525-9660 | Porto Alegre | v. 4 | n. 2 |

p. 80-99 | Jul/Dez. 2018 